\title{
Humanidades médicas no Reino Unido: uma tendência mundial em educação médica hoje
}

\author{
Medical humanities in the UK: a world trend \\ in medical education today
}

\author{
Maria Sharmila A. Sousa', Dante M. C. Gallian², Rui M. B. Maciel ${ }^{3}$
}

Sousa MSA, Gallian DMC, Maciel RMB. Humanidades médicas no Reino Unido: uma tendência mundial em educação médica hoje / Medical humanities in the UK: a world trend in medical education today. Rev Med (São Paulo). 2012 jul.-set.;91(3):163-73.

RESUMO: Este artigo tem por objetivo apresentar uma análise crítica do estado-da-arte da literatura sobre o movimento de introdução das Humanidades Médicas em Educação Médica no Reino Unido, assim como as percepções e atitudes de estudantes de Medicina, acadêmicos e pesquisadores na área. Para tal foi realizada uma revisão crítica de literatura nas bases Ovid-SP e Scopus para os descritores na língua inglesa 'medical humanities', 'medical education', 'humanities', 'humanisation', 'physicians', 'patients', 'medical students', 'British', 'England', no período de 2000 a 2011, com publicações em língua inglesa e por referência cruzada. Tal pesquisa gerou um resultado de 34 artigos, dos quais 29 encontram-se diretamente referenciados neste texto que mostra a maneira como as Humanidades Médicas passaram a ser uma florescente disciplina a ser introduzida em Escolas Médicas a partir da década de 1950, paralelamente entre E.U.A. e Reino Unido. Neste panorama, historicizamos as origens do processo de dissolução do 'bom médico' e delineamos o caminho por meio do qual o Reino Unido configurou-se como o berço da atual tendência mundial de humanização dos cuidados em saúde. Desta maneira, o Reino Unido tem liderado o debate mundial com sua ampla experiência nas Humanidades em Saúde, primeiramente como instrumento de formação ética em saúde e, mais recentemente, como linha de pesquisa para investigar os efeitos observados na integralidade da formação de médicos produzidos pelos variados modelos de sua implementação em suas Escolas Médicas após a publicação dos Médicos de Amanhã pelo General Medical Council em 1995, cujo objetivo é o de resgatar o 'good doctor', o 'bom médico', para a prática clínica.

DESCRITORES: Humanização da assistência; Literatura de revisão como assunto; Educação médica; Ciências humanas/ ética; Reino Unido.
ABSTRACT: This editorial aims to present a critical analysis of the state-of-the-art literature on the initiative of introduction of the Medical Humanities into Medical Education in the United Kingdom, as well as the perceptions and attitudes of medical students, scholars and researchers in this field. For such purpose, a critical literature review was performed at the online bases Ovid-SP and Scopus for the keywords in the English language 'medical humanities', 'medical education', 'humanities', 'humanisation', 'physicians', 'patients', 'medical students', 'British', 'England', during the period from 2000 to 2011 , also collecting publications by cross-referencing. This search produced a result of 34 papers, from which 29 were directly referenced in this work that shows the way through which the Medical Humanities became a flourishing discipline to be introduced in Medical Schools from the 1950's on, simultaneously in the US and the UK. At this panorama, we historicised the origins of the dissolution process of the 'good doctor' and delineated the pathway by which the UK has become the focus of a worldwide trend in humanisation of the health care. As such, raising the world debate with the British both wide and effective experience of introduction of the Medical Humanities, firstly as an instrument for the ethical education in health, then, more recently, as a research strength to investigate the observed effects of the integrity in the education od doctors produced by its several formats implementation across the Medical Schools in the UK, after the publication of Tomorrow's Doctors by the General Medical Council in 1995, whose main aim was to "rescue" the 'good doctor' back into the healthcare.

KEYWORDS: Humanization of assistance; Review literature as topic; Education, medical; Humanities/ethics; United Kingdom.

Laboratório de Endocrinologia Molecular e Translacional, Disciplina de Endocrinologia, Departamento de Medicina, Escola Paulista de Medicina, Universidade Federal de São Paulo, São Paulo, SP.

${ }^{1}$ MSc Medicine, Science \& Society, School of Social Sciences \& Public Policy, King's College London, University of London; Mestre em Ciências, Disciplina de Endocrinologia, Departamento de Medicina, Escola Paulista de Medicina, Especialista em Medicina Farmacêutica, Programa de Extensão Acadêmica, e Membro-Relatora do Comitê de Ética em Pesquisa, Universidade Federal de São Paulo.

2 Professor Adjunto e Diretor do Centro de História e Filosofia das Ciências da Saúde (CeHFi), Programas de Pós-Graduação em Saúde Coletiva e Ensino em Ciências da Saúde, Escola Paulista de Medicina, Universidade Federal de São Paulo.

${ }^{3}$ Professor Titular de Endocrinologia, Diretor do Laboratório de Endocrinologia Molecular e Translacional, Disciplina de Endocrinologia, Departamento de Medicina, Escola Paulista de Medicina, Universidade Federal de São Paulo.

Endereço para correspondência: Maria Sharmila Alina de Sousa. Rua Pedro de Toledo 669, 11ํ andar, Vila Clementino, 04039032, São Paulo, SP, Brasil. e-mail: sharmila.sousa@gmail.com / sharmila.alina @ unifesp.br 


\section{Relação médico - paciente: quem é o urgente- mente requisitado 'Bom Médico'?}

O empobrecimento das relações entre médico e paciente, com suas mais diversas consequências, tem sido um tema que vem suscitando importantes discussões e ações em diferentes âmbitos da sociedade, da política e da cultura no mundo inteiro. No Reino Unido, uma série de reinvindicações causaram uma longa investigação sobre a performance de médicos, laboratórios e instituições de saúde do National Health System (na sigla NHS), o sistema público de saúde britânico, para verificar inadequações à respeito da estrutura do próprio sistema e sobre os procedimentos implementados ao público'. Tais críticas têm suas origens no fato de que a prática médica tornou-se excessivamente técnica e, desta maneira, deixou para trás a sua arte para dar lugar ao sempre prolífico conhecimento científico e suas inovações tecnológicas. Durante este processo, a relação médico-paciente perdeu seu aspecto original: passou de uma associação entre dois seres humanos à mera consulta sobre fatos e números, como se o paciente fosse um conjunto de órgãos em mau funcionamento, e o médico, um mero provedor de tecnologias.

A literatura científica já cobriu vastamente a dissolução das relações médico-paciente, buscando razões de quando, onde e porque isto pode ter acontecido ${ }^{2}$. Logo, tendo se tornado um dos temas contemporâneos mais candentes, pesquisadores da área têm proposto algumas alternativas para o caminho inquietante que o cuidado médico assumiu, por meio de sugestões de uma mudança completa nos sistemas de Educação Médica no Reino Unido. Todavia, tais modificações têm suscitado discussões adicionais sobre os conceitos e fins originais da Medicina, que parecem ter-nos levado à reconfiguração do conceito do 'bom médico' - "o médico que escuta"3.

Por conseguinte, uma maneira de explorar o racional que sustenta tais debates contemporâneos, é identificar as razões pelas quais chegamos a tal estágio de desumanização em Saúde. Desta forma, propomos primeiramente ressaltar como foi cunhada a presente imagem do 'bom médico' no Reino Unido, que todos pacientes anseiam, detendo-nos principalmente na imagem como fonte para tais reivindicações, dado que sua definição aparece como fonte de grande controvérsia. Em seguida, após delinear os principais fatos sobre como as Humanidades Médicas tornaram-se a melhor opção para 'criar o bom médico', iremos nos aprofundar nas percepções e atitudes de estudantes, docentes e pesquisadores na área de Educação Médica no Reino Unido até o momento. Por fim, ressaltaremos alguns dos aspectos-chave de tal tendência dentro da corrente histórica das Humanidades Médicas no Reino Unido. Este debate é bastante relevante, dado que, por seu pioneirismo, o desenvolvimento das Humanidades Médicas no Reino Unido, assim como nos Estados Unidos da América do Norte (E.U.A.), acabaram por se tornar um referencial para tal importante discussão em nível mundial, inclusive no Brasil.

Para tal retomada das origens do 'bom médico' no Reino Unido, a metodologia empregada foi a de revisão crítica de literatura realizada nas bases Ovid-SP e Scopus para os descritores na língua inglesa nas seguintes associações: ((medical OR medicine) AND (humanities OR humanisation OR humanization)) AND (literature AND medicine) AND ((medical OR medicine OR physician OR patient OR medical student) AND (education OR educational OR teaching OR pedagogy OR instruction OR didactic)) AND (British OR England). O período determinado foi o de 2000 a 2011, delimitando apenas publicações em língua inglesa, e por referência cruzada. Tal pesquisa gerou um resultado de 34 artigos, dos quais 29 encontram-se diretamente referenciados neste texto. Outros 30 artigos foram compilados para fins de comparação com o contexto das Humanidades Médicas nos E.U.A. durante o mesmo período. Logo, fica claro que a atividade acadêmica de ensino e pesquisa sobre a temática Humanidades Médicas e Educação Médica foi muito mais prolífica durante este período no Reino Unido, quando em comparação com os E.U.A. e demais localidades. Partimos, então para a contextualização mundial da busca pelo 'bom médico' no Reino Unido.

\section{A busca pelo 'Bom Médico' no Reino Unido: o contexto de uma necessidade mundial}

"A Medicina surgiu da empatia original do homem para com o homem, do desejo de ajudar aqueles em sofrimento, necessidade e doença"4. Devido ao nosso instinto de autopreservação ou a nossa simples vontade de aliviar o sofrimento de um ente querido, uma doença é um evento que nos lembra da fraqueza atávica de nossas limitações, quando comparadas à Natureza. Neste sentido, pessoas doentes precisam de mais ajuda do que outras. Raramente, entretanto, estes são percebidos apropriadamente por aqueles que estão à sua volta. Logo, aqueles capazes de identificar e assistir pessoas doentes foram reconhecidos como misteriosos ou míticos nas sociedades antigas e atuais. Na maioria das culturas e civilizações, a adoração ao misterioso e ao mítico constituíram um sinal de nossa consciência sobre nossas limitações ${ }^{5}$.

Atualmente, os seres humanos ainda mantêm 
tais ideias sobre aqueles que incorporam tais habilidades médicas 'míticas', as quais são vistas como um tipo de solidariedade e visam trazer a 'bondade' ao outros. As pessoas tendem a reconhecer o termo 'bom médico' como sendo uma rótulo descritivo que denota que o médico alcançou determinadas competências desejadas ${ }^{1}$. Por meio da ética de virtudes, é mais fácil explicar este parâmetro de atividade daquelas que verdadeiramente incorporam a virtude (i.e. o médico), devido ao fato de que, atuando como um "compasso interno", a ética de virtude considera aqueles tipos de atitudes que um médico deve ter para realizar suas obrigações profissionais, de acordo com padrões, diretrizes e agendas de prática médica que estão descritos e são largamente aceitos pelas associações médicas mundiais ${ }^{6}$.

Conforme descrito pela humanista Skelton ${ }^{7}$, "Um bom profissional médico, portanto, é acima de tudo alguém que compreende o contexto de sua prática (...) O sábio profissional tem um entendimento daquilo com o qual ele está envolvido". Esta é a natureza de algumas declarações políticas das quais algumas associações médicas fazem amplo uso para resumir suas atribuições profissionais, via diretrizes e códigos de conduta. Logo, traços pessoais, tais como consciência e reflexão já não são mais suficientes para oferecerem uma garantia de confiança sobre a integridade dos médicos. Ao contrário, médicos passaram a representar um 'repositório de sabedoria'6.

O contexto biomédico depois de 1950 pode ter sido responsável por tal nova concepção. Dado o desenvolvimento de uma série de tecnologias derivadas de novos conhecimentos na área médica, houve uma mudança de paradigma, já que os diagnósticos tornaram-se cada vez mais rápidos e precisos ${ }^{5}$. Todos os avanços científicos e técnicos, portanto, induziram mudanças drásticas na assistência médica, para que a qualidade das análises dos cuidados clínicos alcançasse um ponto mais elevado. Por outro lado, estas mudanças causaram outros dilemas, como a ampla reformulação das unidades ambulatoriais e hospitalares, que passaram a se organizar a partir de critérios de agrupamento de doenças, encorajando o desenvolvimento das especializações médicas, que reduziram o componente 'mítico' do processo de assistência médica e cuidados em Saúde. O consequente desenvolvimento de tais especializações favoreceu o aparecimento do 'médico tecnológico', característica daquele que já não mais desempenha o papel do 'bom médico mítico's.

Teleologicamente, este médico utilitarista, que poderia ser descrito como 'não-mítico', seria mais propenso a considerar que alguma insensibilidade é, na verdade, uma vantagem, pois deveria ser um requisito essencial para elaborar um julgamento exato sobre o bem-estar de um indivíduo. Portanto, conforme Skelton ${ }^{7}$ quando discute o 'médico tecnológico': "Sensibilidade aguçada é sem dúvida uma virtude de alta grandeza, quanto ela não interfere na estabilidade das mãos e na frieza dos nervos". Neste sentido, é comum dizer-se que a atitude apropriada para um medico deva ser a de uma certa frieza para realizar o dever médico da melhor e mais precisa maneira possível, de acordo com os códigos de conduta médica.

Embora o General Medical Council do Reino $U_{n i d o}{ }^{8}$ tenha sido extremamente bem sucedido na listagem de todos os atributos necessários para se 'fazer o bom médico', não existe ainda nenhum consenso sobre a viabilidade do 'bom médico'. Como Polly Toynbee comenta, "Está na natureza de cada profissão estabelecer para si um ideal de caráter e tentar impô-lo da melhor maneira que conseguir para os novos profissionais. Está também na natureza da humanidade falhar na proposição de tais ideais, na maior parte das vezes" . O objetivo, conforme Skelton ${ }^{7}$ discute, não está em listar as qualidades exigidas que dizem respeito à profissão médica, mas, ao contrário, reconhecer o real 'bom médico' de verdade quando se vê um. "Ele ou ela terá expertise clínico aliado à seriedade e à sinceridade de decisão, maturidade e profundidade de caráter. Em suma, o bom médico tem uma personalidade adulta".

Desta maneira, assim como o médico e humanista Gregório Marañón ${ }^{10}$ elucidou no prólogo de um estudo sobre menopausa no início do século XX: "EI humanismo es mucho más gesto y conducta que, em su sentido estricto, saber". Todos os argumentos mencionados até aqui, portanto, não necessariamente significaram que tornar-se o 'bom médico' seja um projeto inviável. Hurwitz ${ }^{1}$ é um dos pesquisadores da área que anunciam que a Educação Médica deve ter como objetivo congregar as habilidades e sensibilidades das Ciências Naturais aplicadas com as habilidades reflexivas do médico humanista. Este tipo de profissional, excelente cientista e humanista, é aquilo que os pacientes desejam, desde que as queixas sobre má assistência médica, como o caso britânico famoso do Dr. Shipman, tornaram-se tão difundidas em tempos presentes.

Deste modo, embora ainda não possamos concordar sobre quais as características que constituem o 'bom médico', é ideal que a Educação Médica deva incutir qualidades humanas aos estudantes de Medicina, ao invés de removê-las ${ }^{9}$. Quando se trata de ensinar, o que seria mais humano do que demonstrálo, simplesmente? Ou seja, talvez pudesse ser muito revelador para jovens e inexperientes estudantes o exemplo de um médico, que após longos cinquenta anos de prática diária, ainda consiga se emocionar 
diante da atitude de um paciente extremamente doente para com a sua vida e para com a sua doença.

Por esta e muitas outras razões que serão aqui abordadas, é dito que as Humanidades Médicas são um caminho interessante a ser percorrido pelas Escolas Médicas a fim de melhor preparar os futuros médicos a se engajarem em uma relação humana profissional que se baseia grandemente na confiança: a relação médico-paciente. A fim de compreender a natureza das Humanidades Médicas é importante historicizar os fatos cruciais sobre sua origem em algumas das Escolas Médicas do Reino Unido.

\section{Humanidades médicas em educação médica no Reino Unido: fatos-chave (2000-2010)}

$\mathrm{Na}$ arena da Educação Médica, as Humanidades Médicas constituem tema de grande controvérsia entre os estudiosos da área, dado que não há um consenso sobre seus objetivos e formas de implementação para estudantes de Medicina por todo o mundo, assim como no Reino Unido. Na década de 1970, as Humanidades Médicas tornaram-se uma tendência crescente nos E.U.A., após as primeiras tentativas de introdução de tal tema em Educação Médica. Desde então, têm sido, como Skelton ${ }^{11}$ descreve, um tema 'florescente' de interesse de pesquisa, cujo produto foi a criação de uma revista especializada - Literature and Medicine Journal da John's Hopkins, uma das Escolas Médicas mais influentes nos E.U.A. e no mundo ${ }^{12}$.

A definição das Humanidades Médicas varia através das instituições de educação superior do Reino Unido, geralmente de maneira complementar. Uma das maiores abordagens sobre o termo, por encarar seus objetivos ao invés de suas bases de conhecimento $^{13}$, foi proposto pelo Centre for Medical Humanities da University College London como “(...) um esforço interdisciplinar e crescentemente internacional que se baseia nas capacidades criativas e intelectuais de diversas disciplinas, incluindo Literatura, Artes, [Poesia], Teatro, Cinema, Música, Filosofia, [É]tica, Antropologia e História, na busca das metas educacionais médicas" 14 .

No Reino Unido, debates sobre a introdução das Humanidades Médicas no currículo da graduação médica tornaram-se um assunto muito candente, tanto intelectualmente, como emocionalmente, depois da publicação de Tomorrow's Doctors ${ }^{8}$, obra que exorta os educadores médicos a inovar e melhorar o currículo da graduação médica. O General Medical Council ${ }^{8}$ britânico exigiu uma mudança radical, portanto significando que um terço do currículo deveria ser oferecido como 'Módulos de Estudos Especiais' (MEEs) opcionais (da sigla SSMs no inglês, Special
Studies Modules), envolvendo diferentes formas de Artes e/ou Humanidades para criar o 'médico humano'14.

Tal 'médico humano', ou melhor, 'bom médico' como alguns dizem, deve estar apto para demonstrar as qualidades mais atavicamente humanas, tais como compreensão, capacidade interpretativa, e sensibilidade ética, ao invés de apenas analisar e categorizar os pacientes através das lentes duras e frias da Ciência, sob critérios de doença e sintomas ${ }^{15}$. Junto a tal proposta, o GMC exigiu em sua diretriz divisora de águas que a literatura, em particular, deveria ser abordada na Educação Médica em nível de graduação para alcançar questões-chave filosóficas incitadas pelo 'entrelaçamento' da natureza humana. Em suma, "se as disciplinas das Humanidades se preocupam elas mesmas com a incorporação e a interpretação das experiências humanas, as 'Humanidades Médicas' deveriam fazer o mesmo para as experiências humanas de doenças, deficiências e intervenções médicas"16.

A implementação dos MEEs em Humanidades Médicas na Educação Médica claramente suscitou grande controvérsia no Reino Unido. Deste modo, após a 'Declaração de Windsor' de 1998, que trouxe as Humanidades Médicas à atenção de todos, a Nuffield Trust promoveu uma série de debates sobre o tema a fim de facilitar uma melhor comunicação entre aqueles que já estavam praticando as Humanidades Médicas em suas instituições, além de aumentar a consciência sobre este florescente campo no ensino superior ${ }^{13,14}$. Ambos colóquios culminaram no lançamento de dois centros para as Humanidades Médicas: o Centre for Arts and Humanities in Health and Medicine da University of Durham e o Centre for Medical Humanities da University College London. Após toda a exposição pública sobre o tema, uma revista especializada foi criada - o Journal of Medical Ethics: Medical Humanities ${ }^{12}$.

Estes tempos de mudanças para a Educação Médica alcançaram seu clímax com a fundação, em 2002, de uma Associação de Humanidades Médicas em Birmingham ${ }^{12}$. Este foi um passo crucial para melhor legitimar as Humanidades Médicas como uma área atual e ativa em Educação Médica no Reino Unido a partir deste momento. Adicionalmente, isto abriu espaço para a publicação de numerosos artigos em Ciências Sociais objetivando investigar se os estudantes de Medicina por vezes, ou nunca, apresentam o hábito da leitura por lazer ${ }^{17}$; como eles percebiam a introdução dos MEEs de Humanidades Médicas nos respectivos currículos acadêmicos; e qual era a popularidade de tais módulos dentre os estudantes de Medicina ${ }^{18}$.

Ademais, sociólogos também se preocuparam 
em investigar sobre a aceitação e as dificuldades enfrentadas com os MEEs de Humanidades Médicas por estudantes ou pesquisadores da área ${ }^{17-19}$. Eles também estavam interessados nas razões e sobre como empregar as diferentes formas de Artes e/ou Humanidades a fim de deflagrar a conscientização dos alunos sobre a amplitude de novas ferramentas que poderiam ganhar após passarem pelo 'ensino' das Humanidades para se tornarem o verdadeiro médico 'humano', ou melhor, o 'bom médico', como ambicionado pelos MEEs de Humanidades Médicas ${ }^{20}$. $\mathrm{Na}$ sequência destas investigações, alguns estudos analisaram a maneira através da qual os estudantes têm percebido e avaliado suas experiências com as Humanidades Médicas em Escolas Médicas pelo Reino Unido.

\section{Humanidades médicas em educação médica: a perspectiva dos estudantes do Reino Unido}

Alguns estudantes de Medicina em Liverpool tenderam a notar que o novo Módulo de Estudos Especiais (MEEs) - Humanidades Médicas - introduzido ao seu currículo não foi tão elucidativo, porém particularmente providencial em melhorar suas habilidades de apresentação e comunicação ${ }^{13}$. Outros, ao contrário, acharam que todos os cursos baseados nas Artes e em Literatura foram uma maneira bastante interessante para escaparem dos módulos das 'ciências duras' com os quais eles estavam tão acostumados e, por vezes, saturados ${ }^{12}$. O campo das Humanidades Médicas, todavia, é muito mais complexo do que este simples 'amor ou ódio' para com as Humanidades ou a 'Humanização' dos sistemas médicos deteriorados de hoje. Por que, então, os estudantes de Medicina têm que ler Literatura, Poesia, ou até fazer Artes para se tornarem melhores médicos? Por que é tão importante que um médico apresente, além de domínio de sua Ciência de modo tecnicamente eficiente, uma perspectiva mais abrangente, considerando-se os interesses particulares de seus pacientes e as dificuldades de se enfrentar uma doença em qualquer momento?

"As Humanidades Médicas tratam sobre o desafio para que o atual modelo de Medicina torne-se mais amplo, para que inclua o entendimento científico ao lado da estética e das Humanidades"21. As Humanidades Médicas tratam da reflexão sobre as perspectivas das pessoas (sejam elas pacientes ou médicos) como simples seres humanos, ou seja, seres cujas dimensões corporais, emocionais, psicológicas e espirituais encontram-se estreitamente entrelaçadas. Afinal, como bem descreve Merleau-Ponty, "é a nossa carne que determina como sabemos ou experimentamos alguma coisa"16. Por todas estas razões acima mencionadas, como têm sido largamente discutido por outros autores ${ }^{11,18,20}$, a literatura é essencial por si só, com ou sem qualquer relevância médica e/ou clínica a ser acrescentada a seu prévio valor.

Muitos analistas ecoaram a afirmação de Paracelso: "Medicina não é apenas uma Ciência, é também uma arte". Ao combinar Ciência e Arte, a Medicina pode ser prolífica na tentativa de investigar e compreender a vida humana como um todo, sem enfocar exclusivamente no estudo de suas partes constituintes. Devido a esta prática reducionista da arte médica, houve uma insatisfação sempre crescente entre estudantes e profissionais. Logo, o que poderia ser mais esclarecedor do que perguntar a jovens aspirantes a médicos durante sua Educação Médica sobre seus pensamentos a respeito das atuais abordagens de tal arte? Quando indagados sobre seus hábitos de leitura, a vasta maioria dos estudantes de Medicina da Escola Médica de Newcastle revelaram uma lista longa e surpreendente de suas leituras de lazer, que apresentam ao lado de seus livros de referência para a formação científica. Estas listas eram longas mesmo quando comparadas àquelas dos alunos de Biologia e de Direito. Entretanto, todos os estudantes declararam dedicar menos horas para leitura de lazer após entrarem na universidade, em comparação à época em que estavam no ensino médio ${ }^{17}$.

Alguns temas emergiram quando foram questionados sobre as razões para tal mudança em seus hábitos de leitura. Alguns estudantes de Medicina declararam que seu novo ambiente social - morar com amigos em residências estudantis - forçaramnos a serem mais sociáveis. Dada a existência de uma grande variedade de atividades a realizar, tais como esportes ou socialização no geral, passar mais tempo com os amigos parecia ser bem mais atraente do que sentar em seus respectivos quartos lendo sozinhos. Desta maneira, eles deveriam desenvolver novas atitudes de interação para ter uma pausa dos estudos. Outros culparam a falta de dinheiro ou de orientação para comprar novos livros de literatura. Finalmente, alguns estudantes de Medicina reportaram simplesmente que ler não era mais possível devido às longas horas necessárias para o estudo de livros de textos técnicos sobre as Ciências Naturais. Assim, após passarem longos períodos de tempo no cuidadoso aprendizado dos conceitos médicocientíficos, ficavam tão cansados que não estavam mais dispostos a ler e, portanto, terminados seus estudos, só pensavam mesmo em dormir ${ }^{17}$.

Por conseguinte, na perspectiva dos estudantes de Medicina, os estilos de vida do ensino superior tendem a suprimir sua capacidade de dispor de seu tempo livre com a leitura de algum livro por lazer. 
Também parece que as circunstâncias contextuais da universidade e das residências de estudantes têm um efeito opressor, que resultou na redução de seus hábitos de leitura. Logo, se a Educação Médica tem sido, até então, essencialmente reduzida a aspectos técnicos e ao treinamento das 'ciências duras', como podem os futuros médicos tornarem-se um 'bom médico'? Como eles podem aprender a lidar com as dimensões psicológicas, espirituais e emocionais, além das corporais de seus pacientes?

Dada a referida ideia de que o 'bom médico' consegue compreender completamente o contexto de sua prática ${ }^{7}$, as Humanidades Médicas são uma disciplina preocupada em estudar a experiência humana de se estar doente ou saudável, que também objetiva melhor desenvolver a Medicina e a assistência médica. Como uma área interdisciplinar, as Humanidades Médicas envolvem diversas disciplinas, tais como Filosofia, Ética, Literatura, Artes, História, Antropologia, Teologia e Direito ${ }^{21}$. Com todos estes campos diferentes comunicando-se um com os outros simultaneamente, as Humanidades Médicas tentam alcançar a complexidade da ambiguidade, que deve estar presente na mente dos 'bons médicos', quando eles têm que escolher um procedimento médico para um paciente em particular, com suas características singulares sob o ponto de vista social, emocional, psicológica, espiritual, física, filosófica, política, econômica e cultural.

Se, como Bill Noble ${ }^{21}$ diz, "A prática da Medicina dentro de um contexto social é impossível sem o conhecimento da cultura", o que poderia ser culturalmente mais instrutivo, conforme uma séria de estudiosos apontam, do que a Literatura e as Artes? Conforme Skelton et al. ${ }^{20}$ pontuam, a literatura lida com ambivalência ao invés de reducionismo e os indivíduos descobrem valores e significados diferentes ao experimentá-la. Com o acesso à literatura, o leitor é convidado a formular juízos sobre ações e eventos que ocorreram no enredo, portanto, criando crenças e valores éticos próprios ${ }^{21}$. As mesmas conclusões foram afirmadas pela maioria dos estudantes de Medicina logo após assistirem a um Módulo de Estudos Especiais (MEE) de Humanidades Médicas ${ }^{12,17,18,21 .}$ Eles consideraram que o seu desenvolvimento profissional havia melhorado, após terem participado do módulo baseado nas Artes, tanto que se tornaram aptos a melhor avaliar qualquer tipo de literatura, fosse ela relacionada à Medicina ou à ficção.

Lazarus e Rosslynd ${ }^{12}$ explicam que experimentar as Artes pode facilitar a relação médico-paciente, por estimular visões mais aprofundadas sobre padrões de resposta exibidos por pacientes. Os autores também alegam que por meio do enriquecimento da linguagem e das habilidades reflexivas dos profissionais, a experiência das Artes permite que estudantes de Medicina percebam as singularidades individuais e traços sutis de personalidade. Em outro estudo ${ }^{18}$, fica claro que os estudantes de Medicina não manifestaram ceticismo algum para com a literatura, a qual passou a ser vista como uma forma de pensar complementar às abordagens científicas. Logo, por meio da análise das percepções dos estudantes sobre sua experiência com a leitura de livros literários como meio de transformar um tipo de atividade de lazer em algo que poderia melhorar o seu desempenho profissional, pode-se afirmar que a maioria dos estudantes a consideraram uma iniciativa bastante proveitosa. $O$ contato com a literatura os ensinou não somente como aumentar sua conscientização sobre a vida fora da experiência pessoal, mas também como estimular a inspiração e a introspecção, como invocar respostas emocionais, como perpetuar maior interesse pela leitura e por livros, portanto inspirando alunos sobre o curso de seus estudos (adaptado da Tabela 2 em Hodgson e Thomson ${ }^{17}$ ).

"Quando uma atividade pensa sobre seus próprios métodos, suposições, valores, bases de conhecimento e formas características de raciocínio, quando ela se 'torna autoconsciente', ela é, nesta medida, filosófica" (Blackburn apud Evans ${ }^{16}$ ). Podemos identificar este tipo de mudança, por exemplo, quando um estudante de Medicina afirma que "o papel de Atticus Finch, o tipo de pessoa que ele era, relacionou-se em muitos aspectos com o tipo de pessoa que eu gostaria de ser", após a leitura de "O sol é para todos" (no inglês, "To Kill a Mockingbird) de Harper Lee"; quando o aluno diz que a leitura de "A Anatomia de uma Dor" ("Um Luto em Observação", no inglês, "A Grief Observed") de C. S. Lewis "[lhe] ajudou a se conciliar com questões não respondidas, raiva, confusão ... a ver que era possível se expressar"; ou quando um estudante de Medicina revela que "Lords of Poverty" de Graham Hancock, Ihe fez "sentir satisfeito sobre porque eu estava estudando Medicina". Estes exemplos evidenciam aquilo que seria considerado como excelentes observações de um 'bom médico' (adaptado da Tabela 2 de Hodgson e Thomson ${ }^{17}$ ).

Segundo alguns autores ${ }^{17,18}$, mesmo sob uma perspectiva estritamente 'positivista', tais argumentos são suficientes para justificar a manutenção das Humanidades Médicas no currículo médico. Embora alguns estudantes discordaram sobre se a atividade deve ser opcional ou obrigatória, avaliada ou extracurricular, bem como sobre qual formato ela deve ser apresentada, a grande maioria considerou que os médicos devem ser mais amplamente educados para se tornarem não somente tecnicamente mas também humanamente competentes. Alguns deles também apontaram sua falta de leitura de lazer desde que haviam entrado na universidade, e consideraram 
que a leitura lhes deu uma sensação gratificante ao invés de tédio ${ }^{17,18}$. Portanto, apesar de toda a controvérsia sobre as Humanidades Médicas no Reino Unido, estas tornaram-se hoje em dia uma alternativa interessante para os estudantes ampliarem suas capacidades pessoais e profissionais, mesmo que não seja uma iniciativa tomada por todas as instituições de Educação Médica britânicas.

A percepção dos alunos de Medicina sobre o formato e o conteúdo dos MEEs de Humanidades Médicas envolveram as seguintes temáticas, conforme adaptado da Tabela $1^{18}$ : aumento da empatia pelos pacientes; maior variedade de experiência sob a perspectiva do paciente; capacidade interpretativa aumentada (habilidade de interpretar o que é dito e o que permanece não dito, mas perceptível ao médico sensível e experiente); perspectiva ampliada da condição humana e da doença; auxílio na moral e na compreensão mais aprofundada das complexidades da humanidade; metodologia mais eficaz para estudar os dilemas éticos (a literatura como promotora de reflexão); ênfase na importância da comunicação entre médicos, pacientes e outros profissionais da saúde; e aumento da cultura.

Dados que todos estes temas são relevantes sobre as vantagens de se ter uma disciplina de Humanidades Médicas no currículo médico, é importante ressaltar que Lazarus e Rosslynd ${ }^{12}$, ao conduzir um estudo sobre um módulo de Artes na Escola Médica de Leicester Warwick, ficaram bastante surpresos ao descobrir que uma elevada porcentagem de seu grupo de alunos de Medicina "escreviam poesia, pintavam ou tocavam música de forma comprometida". Adicionalmente, estes mesmo alunos afirmaram que um de seus principais interesses em participar dos MEEs em Humanidades Médicas foi para resgatar um antigo interesse que tinha sido deixado de lado, desde que entraram na Escola Médica. Os autores também demonstraram que esta foi uma maneira que os alunos de Medicina encontraram para "manter contato com um 'eu' que a formação médica não mais Ihes deixava tempo para, e que sentiam em risco, uma vez que estava distorcido pelos constantes 'fatos e números' [a serem compreendidos e memorizados]".

Posteriormente, outras experiências de várias instituições de ensino superior com as Humanidades Médicas em Educação Médica vieram ao conhecimento público no Reino Unido, pois humanistas e pesquisadores na área vêm tentando avaliar sua aplicabilidade, viabilidade e eficiência, como meio de formar o 'bom médico'13,14. Neste sentido, ressalta-se a importância sobre o enfoque na percepção atual de docentes e pesquisadores, as potencialidades que as Humanidades Médicas na era tecnológica trazem para o domínio da Medicina e da assistência médica, incluindo preocupações sociais mais amplas, como a necessidade de conhecimento, a relevância de sua produção e a pesquisa por formas de se fazer 'bom' uso disso.

\section{Humanidades médicas em educação médica: a perspectiva dos pesquisadores no Reino Unido}

Em essência, "o pupilo de 18 anos, que dedicase exclusivamente às Ciências [Naturais], não é mais o adequado para a prática da Medicina"22. Esta é a maneira como Cowley ${ }^{22}$ resume a maneira como acadêmicos, pacientes têm se queixado sobre a assistência médica, desde que os avanços tecnológicos e científicos ampliaram o abismo entre os pacientes e os seus médicos. Assim, educadores e órgãos reguladores neste campo, entre os quais o General Medical Council britânico, por exemplo, decidiu intervir e publicar um documento - "Os Médicos de Amanhã " (no inglês, "Tomorrow's Doctors") ${ }^{8}$ - a fim de questionar radicalmente a metodologia pela qual a Educação Médica no Reino Unido - e de outros lugares - transformou-se em mero treinamento técnico-científico ao invés de indicar aos jovens estudantes de Medicina os caminhos da profissão vocacional que a Medicina verdadeiramente é. Como Evans ${ }^{23}$ convincentemente argumenta, há propósitos divergentes sobre estes conceitos de treinamento e educação.

Portanto, o que, então, os acadêmicos na área de Assistência Médica e de Educação Médica consideram as características verdadeiramente adequadas para o 'bom médico'? Especialistas argumentam que ser capaz de formular um bom diagnóstico clínico implica na consideração de ambas as habilidades, a técnica e a humana. Quanto às habilidades técnicas, um graduado em Medicina deve ter a compreensão científica e dominar os métodos e maneiras da obtenção de evidências (tanto científica, como tecnicamente). Por outro lado, o juízo humano implica que, por meio da educação pelas Artes e Humanidades, os jovens médicos devem desenvolver suas percepções sobre a ética e o nível de educação (adaptabilidade, desenvolvimento pessoal e perspectiva ampla). Adicionalmente, devem melhorar suas capacidades de interpretação e perspicácia, decorrentes da educação pelas Artes e Humanidades, as quais devem permear ambos os julgamentos: o técnico e o humano (adaptado da Figura 1 de Macnaughton ${ }^{15}$ ).

O que acadêmicos e pesquisadores no campo das Humanidades Médicas tentam demonstrar é a maneira pela qual a Medicina, as Artes e as Humanidades misturam-se e como as Ciência e as Artes têm sido historicamente inter-relacionadas e são, em alguns aspectos, inseparáveis. Evocando, portanto, estudos de Anatomia Humana de artistas, tais como Leonardo da Vinci e Andreas Vesalius, romances como "A Morte" de Ivan llitch de Tolstói (no inglês, 
"Death" of Ivan Ilych) e "Admirável Mundo Novo" de Aldous Huxley (no inglês, "Brave New World"), peças de teatro como as de Shakespeare, ou mesmo filmes recentes como "Gattaca", ilustram como a Ciência têm proporcionado inspiração às Artes e vice versa ${ }^{24}$. Considerando todos estes dados, fica bastante claro que o argumento para a inclusão das Humanidades Médicas em Educação Médica no Reino Unido já foi amplamente debatido para os currículos de graduação ${ }^{11-29}$. Todavia, a polêmica ainda não alcançou tal extensão para os currículos de pós-graduação médica, embora tenha sido dito que "nos E.U.A., onde a Medicina é estudada como uma disciplina de pós-graduação e uma proporção substancial dos alunos entram na Faculdade de Medicina após uma licenciatura anterior nas Artes Liberais, suas Escolas de Medicina ensinam Humanidades Médicas como rotina" ${ }^{30}$. No Reino Unido, por outro lado, embora estes debates sejam frequentes, ainda estão limitados ao treinamento de pós-graduação em Psiquiatria e nos cursos de Desenvolvimento Profissional Continuado ${ }^{14,30}$.

Opondo-se à ideia recorrente de que "os estudantes de verdade têm de pensar, ao passo que os estudantes de Medicina têm de meramente regurgitar"28, alguns acadêmicos e pesquisadores no campo das Humanidades Médicas propuseram diferentes caminhos para se obter uma análise aprofundada de Literatura, Cinema, Música e Artes, por meio do cultivo das capacidades criativa, afetiva e reflexiva dos estudantes de Medicina. Por conseguinte, enquanto alguns estão mais preocupados com o conteúdo ${ }^{11,30}$, outros continuam a se preocupar com a resposta dos alunos sobre a abordagem dos MEEs, como uma maneira de melhorar a implementação das Humanidades Médicas ${ }^{17,18,24}$, ambos nos níveis de graduação e de pós-graduação.

Kirklin et al. ${ }^{28}$ salientam o valor de discussões, dedicadamente guiadas por tutores, sobre uma obra de arte ou de literatura, que se concentram sobre questões medicamente relevantes. Esta discussão pode ser útil aos estudantes, auxiliando-os em suas melhorias para a rotina diária futura, especialmente quanto se trata de ser simpático aos pacientes e familiares em cenários complexos tais como no diagnóstico e condutas clínicas em casos de câncer. Os autores também enfatizam a importância de se mostrar como estudantes distintos trabalham de maneira cooperativa com colegas profissionais da área de saúde, demonstrando, através do envolvimento em trabalhos em equipe sobre desenhos e apresentações teatrais que exploram, por exemplo, os dilemas psicossociais associados a se viver com o câncer. Outro objetivo relevante de tal abordagem é possibilitar que os estudantes de Medicina percebam o potencial que as Artes 'per se' têm para expressar as emoções que o câncer evoca em oncologistas e os benefícios que todo este processo 'humano' pode oferecer tanto ao artista - o médico - quanto àqueles que veem seu trabalho - os pacientes, seus familiares e a sociedade. Logo, as Humanidades, de modo geral, são enquadradas como um excelente meio através do qual as emoções e atitudes podem ser comunicadas em profundidade.

Skelton et al. ${ }^{11}$ também ressaltam que escolher exclusivamente literatura medicamente relevante para proporcionar aos estudantes de Medicina tal experiência de leitura profundada é uma opção bastante ingênua, pois a literatura - sendo uma prova viva dos sentimentos, atitudes e respostas de uma pessoa real sobre a vida - retrata como os eventos acontecem simultaneamente e é válida por si só. Consequentemente, através do senso de confusão de um personagem literário, 'como se ele estivesse doente ou talvez drogado', o propósito das imagens e da literatura em geral, é o de abrir possibilidades por meio dos múltiplos significados das palavras, de modo a aumentar a curiosidade do estudante e ampliar a compreensão das histórias de doença dos pacientes. De fato, afirma-se que isto é o que os médicos devem investigar - a compreensão da narrativa do paciente sobre o seu sofrimento, de maneira tal, que o médico perceba a importância da doença para aquele paciente em particular e, potencialmente, para a sua família. Assim, o médico estaria apto a aproximar o cuidado médico da forma mais 'humana' pela qual seria capaz de fazê-lo. Desta maneira, o médico deve confiar não apenas no maneirismo técnico das diretrizes para salvaguardar seguras condutas clínicas, como afirma Dr. Rieux em "A Peste" (no inglês, "The Plague"), de Albert Camus: "Ali jaz certeza, na rondas diárias. Todo o resto segurava-se em meras linhas e triviais contingências; você não podia desperdiçar seu tempo com aquilo. O mais importante era fazer o seu trabalho como ele deveria ser feito"11.

O problema com a literatura, por outro lado, reside em sua 'irredutibilidade ('Ser ou não ser' não pode ser reduzido a 'eu estou tendo pensamentos autodestrutivos') [pois isto] a faz parecer não-científica, e por extensão flexível"20. Entretanto, devemos abordar a literatura como uma forma de pensar, porque a Música, a Poesia e as Artes, em geral, alteram nossa forma de enxergar o mundo e nossa própria compreensão dos outros e de nós mesmos. E, apesar do equívoco popular de que a 'Ciência seja uma coleção de fatos concretos', há outras maneiras de se avaliar o feito das Ciências Humanas, popularmente ditas 'flexíveis', sobre os estudantes de Medicina. Embora Hume seja bastante cético sobre a construção do 'bom médico', "forte senso, unido a um sentimento delicado, melhorado pela prática, aperfeiçoado pela comparação e livre de qualquer preconceito"20 não seria uma maneira concebível de se fazer o 'bom médico', argumentam 
Skelton et al..$^{20}$. Por este motivo, quando os estudantes revelam que o período durante o MEE de Humanidades Médicas foi a 'primeira vez que realmente lhes perguntaram sobre o que eles pensavam', ou quando um jovem médico durante sua educação profissional continuada afirmar que esta foi a 'primeira vez que Ihe perguntaram o que sentia', estes casos podem sugerir que seria importante considerar as eficazes formas de 'humanização' que a Literatura e as Artes trazem dentro do escopo dos Médicos de Amanhã do GMC.

Macnaughton ${ }^{15}$ ainda ressalta as visões diferentes dos estudantes de Medicina sobre os MEEs em Humanidades Médicas. Além do valor instrumental das Humanidades, que deriva do fato delas não apenas proverem os estudantes de Medicina com melhores habilidades de escrita, mas também estimularem a sua criatividade, o valor não-instrumental da Literatura e das Artes em Educação Médica é a valorização do desenvolvimento pessoal. No entanto, a autora aponta que os menos interessados nestas novas abordagens em Educação Médica são aqueles que mais precisam dela. Ao comparar os formatos do curso de Humanidades Médicas, Macnaughton ${ }^{15}$ explica que, quando o mesmo era voluntário, muitos alunos participavam e apreciavam-no, apesar de não considerá-lo como central para sua Educação Médica. Por outro lado, quando fazia parte do currículo obrigatório do último ano, a maioria dos alunos consideraram-no um tanto pobre e inútil, revelando um problema comum em tais "cursos vocacionais, como o de Medicina: os estudantes tendem a considerar como importante apenas aquelas aulas que eles veem como sendo diretamente relevantes para o trabalho de ser médico"15, tradicionalmente minando a experiência estética das Humanidades.

Um último exemplo sobre o efeito positivo dos MEEs é o curso organizado por Kathy Weller no King's College Hospital em 1998. Ela desvendou os vínculos entre Artes e Medicina usando o corpo humano através de workshops práticos, teoria cultural e sessões clínicas dentro de um contexto de 'cuidado' ao invés de 'cura'. Esta abordagem tornou mais interessantes os progressos dos alunos e revelou o impacto catártico que tal experiência pode ter em suas vidas, tanto como profissionais e seres humanos ${ }^{19}$. Tal encontro com as Artes, portanto, demonstrou que a florescente experiência estética pelas Humanidades não é apenas essencial, mas também 'mítica', no sentido de catarse, para ambos profissionais e pacientes.

\section{Humanidades médicas em educação médica no Reino Unido atual: tendência ou fato?}

Com esta evidência, um leitor mais apressado poderia concluir que as Humanidades Médicas tornaram-se, ao longo dos últimos dez anos, um fato sólido em Educação Médica do Reino Unido. Todavia, alguns autore ${ }^{25,26,29}$ argumentam que, ao contrário, deveriam permanecer como uma tendência, pois ainda não há um consenso dentre os especialistas, nem sobre o modo de como implementar os MEEs em Humanidades Médicas, nem como avaliá-los adequadamente. Há outros que chegam a questionar sobre a existência de um conjunto de regras relativas a um único formato para tal módulo, devido a seu próprio intuito - a 'de-mecanização' dos estudantes de Medicina. A maior razão por trás de tal controvérsia é o fato de que as Humanidades Médicas são consideradas um instrumento potencial de governança. Logo, é importante explorar o que poderia ser entendido por governança, tal como Evans ${ }^{26}$ elabora sobre 0 assunto.

Embora seja salutar, como Evans ${ }^{26}$ coloca, diferenciar 'governança' - "a noção do processo de regulamentação interna" ou simplesmente "autoregulação" - de 'governo' - "o aparato de regulamentação mandatória sobre nossos assuntos por aqueles que nos governam" - Petersen e colegas, ao contrário, tendem a considerá-la como o "processo de condução ou de guiar os outros ou o próprio comportamento - no sentido Foucaultiano, 'a conduta da conduta"' (Burchell et al. apud Petersen et al. ${ }^{29}$ ). Por tal consideração, os autores recorrem a ideia de 'formação de identidade' de Foucault com a qual ele afirma que o "currículo como um texto estético e ético deve funcionar não apenas para apoiar o aprendizado de conhecimentos e habilidades mas também o aprendizado de valores e atributos que constituem uma identidade"25. Tal 'formação de identidade' é como uma "'estética da existência' na qual criamos a nós mesmo como a uma obra de arte"25. Ou seja, como Bleakley et al. ${ }^{25}$ diretamente colocam a questão, o currículo médico deve ser concebido de modo inteligente para transformar os estudantes, através do processo 'estético e ético de auto-formação', em seres humanos em sua integralidade.

No significado mencionado de 'formação de identidade', o que poderia ser mais humano, reivindica-se, do que a introdução da experiência estética das Humanidades (Literatura, Artes e Música) nos currículos médicos no Reino Unido? No entanto, um leitor mais cauteloso pode indagar: quem está defendendo que médicos devam ser mais humanos: os pacientes ou a sociedade? Talvez, seria esta uma "falha sistêmica de uma prática reflexiva individualizada, compensando ambos, o excesso de trabalho estruturalmente induzido e a má gestão com as Artes?"29. Neste sentido, o que tem sido disfarçado como anseios pelo 'bom médico' pode, na verdade, ser uma ferramenta governamental de autopreservação usado por aqueles que não conseguem agir perante 
os dilemas administrativos devidos a questões de forças políticas e disputas de poder dentro dos sistemas de Assistência e Educação Médicas.

Assim, poderiam as Humanidades Médicas vir a ser uma desculpa para uma nova forma de tirania administrativa? Porque, afinal, todos devemos estar cientes de que "projeto e implementação do currículo são, ambas, formas inescapáveis de governo e o convite moral para 'ser humano', portanto, oferece um paradoxo: se o apelo à humanidade emergente dos alunos de Medicina é usado como um instrumento de governança, então não podemos simplesmente seguir em frente com o plano de educar moldando os atributos do 'bom médico', um profissional humano, como se isto fosse não-problemático, transparente e garantido através de responsabilização"25. Portanto, a produção de 'bons médicos' poderia se transformar em uma falácia, pois "em uma época que parece querer transformar tudo em números, podem não haver desenlaces prontamente específicos ou intangíveis, que reflitam o cuidado em saúde humanizado de maneira alguma (...) poderemos ser capazes de saber quando o vemos, mas poderemos não ser capazes de oferecer algoritmos que resultem nele"26.

Consequentemente, "é preciso cautela com os perigos da mecanização do 'humano'"'26, pois não existe fórmula correta para se fazer o 'bom médico'. Não é suficiente avaliar os estudantes de Medicina após a sua participação em um MEE em Humanidades Médicas simplesmente pela quantificação da aquisição de certos atributos e habilidades, porque isto terrivelmente se assemelharia ao treinamento atual de competências técnicas das Ciências Naturais, popularmente ditas 'duras', as quais o GMC britânico quer com seus Médicos de Amanhã. Com isso, Evans ${ }^{26}$ quer dizer que mesmo que alguém tente chegar a um alvo numérico da 'satisfação do paciente', esta busca apenas nos desviaria de nosso objetivo fundamental, que é alcançar o cuidado em saúde humanizado, através da efetiva humanização da Educação Médica.

Contudo, algumas observações cautelares devem ser delineadas antes que demais conclusões sejam feitas. Primeiramente, é relevante apontar para o currículo um tanto curioso proposto por Giordano ${ }^{24}$, um docente em Humanidades Médicas da University of Manchester, que afirma que um e-modulo (virtual) teria custo-benefício eficiente, melhorando as notas dos exames finais dos alunos por meio de avaliação de materiais via palestras virtuais, bem como os capacitaria a participarem de fóruns online sobre habilidades comunicativas e questões éticas guiados de maneira melhor formatada do que em um debate frente-a-frente. Parece-nos, entretanto, que estes alunos sofreriam de uma falta de interação humana, o que não pareceu representar problema algum para
Giordano, conquanto que os resultados - notas de exames - fossem mantidos nos elevados padrões das Escolas Médicas.

Em segundo, a proposta feita por Cowley ${ }^{22}$ para as políticas de admissão das Escolas Médicas devem ser melhor analisadas antes que outros se entusiasmem em adotar suas ideias. Este autor argumenta que por meio da escolha dos 'candidatos certos' - aqueles que são proficientes tanto técnica como humanamente - não há necessidade alguma para a inclusão das Humanidades Médicas nas Escolas Médicas no Reino Unido. Por proficiência humana, Cowley quer dizer que o aluno candidato deverá ter não só a habilidade empática para compreensão do ponto de vista dos pacientes, e, assim, proporcionar melhor tratamento, mas também maior conhecimento da Escola Médica e sobre si mesmo antes de entrar nela, para aumentar a satisfação com o trabalho e, portanto, o desempenho e a longevidade de sua atuação profissional. Se isto não é um instrumento de governança para critérios de admissão, que ameaça abater avaliações técnicas, mal podemos compreender o que poderia sê-lo.

Consequentemente, ao se indagarem sobre se as Humanidades Médicas são uma maneira para o 'cuidado em saúde humanizado' ou uma questão de 'ferramenta de governança', parece que a resposta dos estudiosos da área seria AMBOS. Fica-se com a impressão de que várias formas de tirania administrativa já foram formuladas anteriormente. Seria, portanto, completamente paradoxal se ao se tentar alcançar tal 'mítica' experiência dos médicos sendo integralmente humanos - como proposta pelo formato dos MEE em Humanidades Médicas - tal processo acabasse incentivando os fatores que comprometem a realização do "bom médico"26. Similarmente, sobre a questão se as Humanidades Médicas são um fato ou uma tendência em Educação Médica do Reino Unido atualmente, é sábio afirmar AMBOS também.

Neste sentido, certamente, os estudos conduzidos neste campo devem ser menos ambivalentes, para que um consenso possa ser concluído, a fim de que, portanto, as Humanidades Médicas, sejam elas Literatura, Artes, Música, Teatro, Cinema, Ética, História, Filosofia, Teologia, Antropologia, Sociologia, Direito, passem a ser vistas com mais seriedade não somente por educadores na área da Saúde, mas também por sociólogos, filósofos e eticistas. Tal como aconteceu no último congresso da Associação Internacional de Bioética (da sigla IAB no inglês, International Association on Bioethics), em Roterdã em junho de 2012, quando dentre as principais palestras e cerimônias de abertura e encerramento de um evento carregadamente sisudo e, por vezes, sufocante, dada a tenacidade dos assuntos ali tratados, foi a beleza e a sensibilidade 
trazida pelas apresentações acrobáticas, de música, canto, filmes e exibições da emergente bioarte pelos corredores do prédio que aliviaram os corações e suscitaram a integralidade do ser daqueles que cuidam do ser humano como tal. Após um evento como este, no qual este debate migrou das tímidas

\section{REFERÊNCIAS}

1. Hurwitz B, Vass A. What's a good doctor, and how can you make one? By marrying the applied scientist to the medical humanist. BMJ. 2002;325(7366):667-8.

2. Gothill M, Armstrong D. Dr. No-body: the construction of the doctor as an embodied subject in British general practice 1955-97. Sociol Health III. 1999;21(1):1-12.

3. Armstrong D. What do patients want. BMJ. 1991;303(6797):261-2.

4. The Evolution of Modern Medicine - A series of lectures delivered at Yale University on the Silliman Foundation [database on the Internet]. Yale University Press; 1921 [cited 2010 Nov 20]. Available from: http://www. gutenberg.org/files/1566/1566-h/1566-h.htm.

5. Gallian D, Reginato V. Relação assistencial e sua humanização. In: Ramos DLdP, editor. Bioética, pessoa e vida. São Caetano do Sul: Difusão Editora; 2009. p. 117-33.

6. MacKenzie CR. What would a good doctor do? Reflections on the ethics of medicine. Hosp Special Surg J. 2009;5:4.

7. Skelton JR. The good doctor. Role play and clinical communication: learning the game. Oxford: Radcliffe Publishing; 2008. p.152.

8. Tomorrow's doctors: recommendations on undergraduate medical education [database on the Internet]. General Medical Council; 1993 [cited 2009]. Available from: http:// www.gmc-uk.org/education/undergraduate/tomorrows_ doctors_2009.asp.

9. The BMJ's wild goose chase. BMJ. 2002;325:i.

10. Marañón G. Vocación y ética. Madrid: Espasa-Calpe Obras Completas; 1976.

11. Skelton JR, Thomas CP, Macleod JA. Teaching literature and medicine to medical students, part I: the beginning. Lancet. 2000;356(9245):1920-2.

12. Lazarus PA, Rosslyn FM. The arts in medicine: setting up and evaluating a new special study module at Leicester Warwick Medical School. Med Educ. 2003;37(6):553-9.

13. Sheard S. Developing history of medicine in the University of Liverpool medical curriculum 1995-2005. Med Educ. 2006;40(10):1045-52.

14. Kirklin D. The Centre for Medical Humanities, Royal Free and University College Medical School, London, England. Acad Med. 2003;78(10):1048-53. reuniões do subsolo da IAB para abranger o palco central das discussões sobre Educação em Saúde, que as Humanidades Médicas começam a trazer o 'bom médico' de volta aos consultórios por todo o mundo efetivamente.

15. Macnaughton J. The humanities in medical education: context, outcomes and structures. Med Humanit. 2000;26(1):23-30.

16. Evans M. Reflections on the humanities in medical education. Med Educ. 2002;36(6):508-13.

17. Hodgson K, Thomson R. What do medical students read and why? A survey of medical students in Newcastleupon-Tyne, England. Med Educ. 2000;34(8):622-9.

18. Lancaster T, Hart R, Gardner S. Literature and medicine: evaluating a special study module using the nominal group technique. Med Educ. 2002;36(11):1071-6.

19. Weller K. Visualising the body in art and medicine: a visual art course for medical students at King's College Hospital in 1999. Complement Ther Nurs Midwifery. 2002;8(4):211-6.

20. Skelton JR, Macleod JA, Thomas CP. Teaching literature and medicine to medical students, part II: why literature and medicine? Lancet. 2000;356(9246):2001-3.

21. Bolton G. Medicine and literature: writing and reading. $J$ Eval Clin Pract. 2004;11(2):9.

22. Cowley C. Polemic: five proposals for a medical school admission policy. J Med Ethics. 2006;32(8):491-4.

23. Evans M. Roles for literature in medical education. Adv Psychiatric Treat. 2003;9:7.

24. Giordano S. Medical humanities: an e-module at the University of Manchester. Camb Q Healthc Ethics. 2010;19(4):446-57.

25. Bleakley A, Marshall R, Bromer R. Toward an aesthetic medicine: developing a core medical humanities undergraduate curriculum. J Med Humanit. 2006;27(4):197-213.

26. Evans HM. Affirming the existential within medicine: medical humanities, governance, and imaginative understanding. J Med Humanit. 2008;29(1):55-9.

27. Kirklin D. Responding to the implications of the genetics revolution for the education and training of doctors: a medical humanities approach. Med Educ. 2003;37(2):16873.

28. Kirklin D, Meakin R, Singh S, Lloyd M. Living with and dying from cancer: a humanities special study module. Med Humanities. 2000;26(1):51-4.

29. Petersen A, Bleakley A, Bromer R, Marshall R. The medical humanities today: humane health care or tool of governance? J Med Humanit. 2008;29(1):1-4.

30. Oyebode $\mathrm{F}$. The humanities in postgraduate medical education. Adv Psychiatric Treat. 2009;19:6. 